\title{
Cross-validation of the Arabic MINI, Module U, for Diagnosis of Premenstrual Dysphoric Disorder and the Arabic Premenstrual Symptoms Screening Tool
}

\section{Rifka Chamali}

Weill Cornell Medical College in Qatar

Rana Emam

Weill Cornell Medical College in Qatar

Ziyad Mahfoud

Weill Cornell Medical College in Qatar

Hassen Al-Amin ( $\square$ haa2019@qatar-med.cornell.edu )

Weill Cornell Medical College in Qatar https://orcid.org/0000-0001-6358-1541

Research article

Keywords: Premenstrual Symptoms Screening Tool, Premenstrual Dysphoric Disorder, Arabs, crossvalidation

Posted Date: January 23rd, 2020

DOI: https://doi.org/10.21203/rs.2.21669/v1

License: (c) (i) This work is licensed under a Creative Commons Attribution 4.0 International License. Read Full License 


\section{Abstract}

\section{Background}

Premenstrual dysphoric disorder (PMDD) is a severe form of premenstrual syndrome (PMS) that affects the functioning and includes various physical, depressive, and anxiety symptoms. The Mini-International Neuropsychiatric Interview, Module U (MINI-U), assesses the diagnostic criteria for probable PMDD. The Premenstrual Symptoms Screening Tool (PSST) measures the severity of these symptoms and provides scores from which we can diagnose PMS and PMDD. The purpose of this study is to obtain the cut-offs from PSST that would fit well with the diagnosis of PMDD using the MINI-U as a gold standard.

\section{Methods}

We administered the Arabic MINI-U and PSST independently to Arab women ( $\mathrm{N}=194)$ in Doha, Qatar. The Wilcoxon-Mann-Whitney test was used to compare the PSST ordinal scores between those who answered Yes vs No on the corresponding MINI-U items. These comparisons were followed by Receiver Operating Characteristics (ROC) analyses using the MINI-U answers as the gold standard to determine the cut-off scores on the PSST, in addition to their sensitivity and specificity measures

Results

The rating of PSST scores for participants who answered Yes in the MINI-U varied from 1.5 (not at all to mild) to 3 (moderate). Receiver Operating Characteristics (ROC) analyses showed that all areas under the curves (AUCs) were significant with the cut-off scores on the corresponding PSST items.

\section{Conclusion}

This cross-validation gives reassurance that the severity measures of PSST can recognize patients with moderate/severe PMS and PMDD who would benefit from immediate treatment instead of waiting another two months.

Keywords

Premenstrual Symptoms Screening Tool, Premenstrual Dysphoric Disorder, Arabs, cross-validation

\section{Background}

Premenstrual syndrome (PMS) is characterized by a collection of mild to severe physical, affective, and behavioral symptoms experienced by about $80 \%$ of reproductive age women $[1,2]$. The symptoms occur cyclically before or during the luteal phase of the menstrual cycle. Premenstrual dysphoric disorder (PMDD) is a more severe form of PMS with a greater emphasis on depressive and anxiety symptoms [3]. The etiology of PMS and PMDD is not clearly understood but the onset of symptoms is associated with hypersensitivity to changes in the ovarian hormonal level during the menstrual cycle [4, 5], dysregulated immune function [3], neurotransmitter dysregulation, stress, diet, and lifestyle [6]. Pharmacological 
interventions include analgesic treatment, combined oral contraceptives [7], and selective serotonin reuptake inhibitors $[8,9]$. Nonpharmacological treatments are lifestyle interventions and cognitive behavioral therapy (CBT).

Overall, 75-85\% of women have experienced PMS symptoms [1, 2] whereas PMDD affects $5-8 \%$ of reproductive age women worldwide [10]. According to the International Classification of Diseases (ICD-10), only one distressing symptom at the time of menstruation is required for PMS diagnosis. It does not consider the severity of the symptoms, and no clear definition exists when PMS becomes clinically significant. Contrarily, diagnosis of PMDD mandates the impairment of functioning by the symptoms [11]. According to the Diagnostic and Statistical Manual of Mental Disorders (DSM-5) [12], the criteria for the diagnosis of PMDD are: (A) at least 5 symptoms must be present in the final week before the onset of menses and resolve within a few days of the onset of menses and these symptoms must occur in the majority of the menstrual cycles, (B) at least one symptom must be marked affective lability, marked irritability or anger or marked depressed mood or anxiety, (C) one or more of the following symptoms must be present: decreased interest in usual activities, difficulty in concentration, increased fatigue, change in appetite, marked change in sleep, feeling overwhelmed or physical symptoms, (D) these symptoms should affect productivity at work or school, relationships, responsibilities, and social activities. These symptoms should not be attributable/resultant to symptoms from (E) another psychiatric disorder or ( $F$ ) physiological effects of a substance. Finally, $(G)$ these symptoms should be confirmed by prospective daily ratings for at least two symptomatic cycles.

The Mini International Neuropsychiatric Interview (MINI) is a structured interview consisting of several modules to diagnose DSM-IV-TR psychiatric disorders [13-15]. Module U (MINI-U) is the corresponding module that measures categorically the presence or absence of symptoms to fulfill diagnostic criteria for PMDD [16]. Prospective daily ratings have to be completed for at least two symptomatic cycles to confirm the diagnosis and are the only way to measure both severity and monitor symptoms over time [17].

The Premenstrual Symptoms Screening Tool (PSST) is an instrument that includes all premenstrual symptoms as well as a measure of impairment as per DSM-IV-TR criteria. It also translates categorical DSM-IV-TR criteria into a dimensional rating scale to assess severity [17]. It is a useful diagnostic tool to capture moderate/severe PMS and PMDD diagnoses in symptomatic women who would benefit from treatment [18].

The MINI-U for diagnosis of PMDD relies mainly on the presence or absence of symptoms, including the impact on functioning, while PSST uses a dimensional scale to measure the severity of symptoms, which ultimately is very important to determine the effects of symptoms on daily activities. There are no studies that compared the diagnostic categorical scales with dimensional measures of severity of PMDD symptoms. Such comparisons would enhance the accuracy of the psychometric measures of the combined approaches when diagnosing and monitoring patients with moderate/severe PMS and PMDD. The availability of valid cut-off scores from PSST tested through answers from MINI-U (DSM criteria) would give more confidence to diagnose PMDD based on the severity measures of PSST. This reassurance would facilitate the initiation of treatment for this group of patients instead of waiting two months, especially that 
the daily recording of symptoms has proven to be very difficult in practice $[19,20]$. Thus, the aims of this study are (1) to compare the responses between the dichotomous MINI-U answers and the scores on the PSST items; and (2) to establish the cut-off scores on the dimensional PSST items by using the categorical MINI-U as a gold standard.

\section{Methods}

This cross-sectional study is part of a project to validate the Arabic version of the PSST [citation deleted to maintain integrity of the review process]. This article reports a secondary analysis of the relationship between answers on the Arabic MINI-U with the corresponding items (see Table 1) in the Arabic PSST. 
Table 1

Corresponding items between PSST and MINI-PMDD

\begin{tabular}{|lcc|}
\hline Symptom & PSST & MINI-U \\
\hline Anger/irritability & 1 & U3 - D \\
\hline Anxiety/tension & 2 & U3 - B \\
\hline Tearful/sensitive to rejection & 3 & U3 - C \\
\hline Depressed mood /hopelessness & 4 & U3 - A \\
\hline Decreased interest in work activities & 5 & U3 - E \\
\hline Decreased interest in home activities & 6 & U3 - E \\
\hline Decreased interest in social activities & 7 & U3 - E \\
\hline Difficulty concentrating & 8 & U3 - F \\
\hline Fatigue/lack of energy & 9 & U3 - G \\
\hline Overeating/food cravings & 10 & U3 - H \\
\hline Insomnia & 11 & U3 - I \\
\hline Hypersomnia & 12 & U3 - I \\
\hline Feeling overwhelmed or out of control & 13 & U3 - J \\
\hline Physical symptoms & 14 & U3 - K \\
\hline Symptoms interfered with: & & \\
\hline Work efficiency/productivity & A & U2 \\
\hline Relationship with co-workers & B & U2 \\
\hline Relationship with family & C & U2 \\
\hline Your social life activities & E & U2 \\
\hline Home responsibilities & 700 ; MINI-U, The Mini \\
\hline PSST, Premenstrual Symptoms Screening & & \\
\hline International Neuropsychiatric Interview, Module U. & \\
\hline
\end{tabular}

\section{Study Setting and Subjects}

The study took place in Doha, Qatar where Arab women were recruited at two Primary Healthcare Centers between October 2013 and March 2014. 
Participants were eligible to join the study if they were Arab females between 18 and 45 years old and with a regular menstrual cycle of 24 to 32 days. The following exclusion criteria were adopted to control for other confounding conditions: (1) taking oral contraceptive pills, hormonal therapy, psychotropic medication, and suspected of being pregnant or in menopause, (2) women with endometriosis, acute thyroid or pituitary disorders or any other acute medical problem and (3) women with a history of drug and alcohol abuse or with an active psychiatric disorder (other than PMDD) diagnosed in the previous six months.

During the recruitment period, a total of 430 women were approached to join the study, and among them, 280 women were eligible for the study. However, only 194 women agreed toparticipate. This sample size was sufficient to detect the projected sensitivity or specificity of 85 percent and an estimated prevalence of severe PMS/PMDD of 20 percent, within a margin of error of 10 percent and a 95 percent confidence interval.

\section{Research Design}

This study is cross-sectional with no interventions, and all participants provided written consent before enrollment. The Institutional Review Boards of Hamad Medical Corporation and Weill Cornell Medicine in Doha, Qatar approved this study. A licensed physician or nurse interviewed participants to confirm their eligibility. The psychiatrists then administered the Arabic Mini International Neuropsychiatric Interview Plus version 6 (MINI-Plus 6) to screen for any psychiatric disorders including PMDD (MINI-U) as per DSM-IV-TR criteria [16]. An independent second rater, blinded to the results of the MINI, collected sociodemographic information, past medical and psychiatric history, smoking and exercise patterns, and administered the PSST. The independent raters were medical students or nurses who were formally trained on how to administer and rate the PSST. Good inter-rater agreement was established before the collection of data. A pilot sample of 20 women were rated independently by more than two raters and the interclass coefficient was 0.89 .

\section{Procedures}

Recruitment for this study commenced shortly after the introduction of DSM-5, no diagnostic instruments were available at the time to diagnose PMDD according to DSM- 5 criteria; hence we used MINI-U that followed DSM-IV-TR criteria. DSM-5 adopted the same criteria for the diagnosis of PMDD as DSM-IV-TR except for minor modifications $[12,13]$.

Module $\mathrm{U}$ in the MINI is a screening and diagnostic tool for PMDD. It is composed of 3 main dichotomous questions (U1, U2, and U3) with the possibility of answering "yes" or "no". The first two questions respectively assess mood changes before menstruation and if the subject experienced any difficulty at work or in usual activities and relationships during these periods. The last question determines the presence of affective, behavioral, and physical symptoms using lettered questions U3-A to U3-K, as indicated in Table 1 . A diagnosis of probable PMDD is reached if the first two questions are answered positively together with at least one affective symptom from U3-A to U3-D and a further four emotional, behavioral, or physical symptoms from U3-E to U3-K [15]. 
Translation of the PSST was approved by the original author [17] and McMaster University. The PSST was translated to Arabic using the repeated forward-backward procedure. All concerns were resolved by modifying the Arabic version of PSST until the original author approved the English back-translated version. Please refer to the study by [citation deleted] for further details on the translation and validation procedures for the Arabic versions. The PSST is composed of two sections. The first section includes a list of premenstrual symptoms followed by a second section that measures impairment following DSM-IV-TR criteria for PMDD. Responses are reported on a severity scale of "not at all," "mild," "moderate" or "severe." The instrument provides the diagnosis of moderate to severe PMS and PMDD to identify patients who would benefit from pharmacological treatments [17].

\section{Statistical Analysis}

All analyses were performed using IBM Statistical Package for Social Sciences (SPSS) for Mac version 24 [21]. The level of significance was set at $5 \%$. Sociodemographic characteristics and clinical features were reported as means and standard deviations (SD) for continuous measures such as age, and as frequency and percentage for categorical measures such as education level. The ordinal PSST scores were reported as the median and interquartile range (IQR). The Wilcoxon-Mann-Whitney test was used to compare the PSST ordinal scores between those who answered Yes vs No on the corresponding MINI-U items. These comparisons were followed by receiver operating characteristics (ROC) analyses using the MINI-U answers as the gold standard to determine the cut-off scores on the PSST, in addition to their sensitivity and specificity measures. We used the highest Youden indices $(J)$ to determine the best cut-off scores on each item in PSST and the corresponding sensitivity and specificity.

\section{Results}

\section{Sociodemographic and clinical characteristics (Tables 2 and 3)}


Table 2

Sociodemographic characteristics

\begin{tabular}{|ll|}
\hline Variables & \\
\hline Mean age (SD), years & $32.12(8.26)$ \\
\hline Country born, $\mathrm{n}(\%)$ & $111(62.0)$ \\
\hline Qatar & $68(38.0)$ \\
\hline Other & \\
\hline Marital Status, $\mathrm{n}(\%)$ & $112(62.6)$ \\
\hline Married & $55(30.7)$ \\
\hline Never Married & $12(6.7)$ \\
\hline Divorced/widowed & \\
\hline Education level, $\mathrm{n}$ (\%) & $11(6.2)$ \\
\hline Elementary or intermediate school & $53(29.9)$ \\
\hline Secondary or High School & $55(31.1)$ \\
\hline Vocational/associate degree & $58(32.7)$ \\
\hline University degree or postgraduate degree & \\
\hline Employment status $\mathrm{n}(\%)$ & $118(66.6)$ \\
\hline Employed & $25(14.1)$ \\
\hline Housewife & $11(6.2)$ \\
\hline Job seeker & $15(8.5)$ \\
\hline Student & $55(30.7)$ \\
\hline Retired & $5(2.8)$ \\
\hline Other & \\
\hline Lifestyle, $\mathrm{n}(\%)$ & \\
\hline Current cigarettes smoker & \\
\hline Current shisha smoker & \\
\hline Regular exercise & \\
\hline SD, standard deviation & \\
\hline
\end{tabular}


Table 3

Clinical features of subjects

\begin{tabular}{|ll|}
\hline \multicolumn{2}{|l|}{ Medical Characteristics, $\mathbf{n}(\%)$} \\
\hline PMS according to PSST & $63(35.2)$ \\
\hline PMDD according to PSST & $25(13.9)$ \\
\hline PMDD according to MINI & $84(46.7)$ \\
\hline Previous diagnoses & \\
\hline Psychiatric diagnosis & $6(3.3)$ \\
\hline Depression & $9(5.0)$ \\
\hline Chronic lung disease & $25(13.9)$ \\
\hline Hypertension & $7(3.9)$ \\
\hline Cardiac disease & $5(2.8)$ \\
\hline Arthritis & $20(11.1)$ \\
\hline Osteoporosis & $9(5.0)$ \\
\hline Kidney disease & $4(2.2)$ \\
\hline Diabetes & $10(5.6)$ \\
\hline Hypercholesterolemia & $20(11.1)$ \\
\hline Cancer & $2(1.1)$ \\
\hline Allergies & $52(28.9)$ \\
\hline
\end{tabular}

From the 194 women who participated in the study, 15 participants were excluded from the analysis (4 elected to withdraw and the remaining met the exclusion criteria). Therefore, the sample consisted of 179 female participants who completed all study procedures. The study sample had a mean age of 32.12 years $(\mathrm{SD}=8.26)$. The majority of participants were born in Qatar $(62.0 \%)$, married $(62.6 \%)$, and employed (66.6\%). Approximately $33 \%$ of participants had a university degree, and $31 \%$ practiced regular exercise. According to the PSST, $14 \%$ of participants had a diagnosis of PMDD, and $35 \%$ had a diagnosis of PMS. However, according to MINI-U, $49 \%$ of participants had a diagnosis of probable PMDD. A minority of participants had been diagnosed in the past with depression (5\%) or other psychiatric illness (3.3\%).

Frequency of symptoms as per MINI-U and PSST (Table 4) 
Table 4

Frequency of symptoms as per MINI-U and PSST

\begin{tabular}{|c|c|c|c|c|c|}
\hline & $\begin{array}{l}\text { MINI-U } \\
\text { (Yes) }\end{array}$ & Not at all & Mild & Moderate & Severe \\
\hline PSST Symptoms & n (\%) & n (\%) & $\mathrm{n}(\%)$ & $\mathrm{n}(\%)$ & n (\%) \\
\hline Anger/irritability & $132(73.3)$ & $23(12.8)$ & $\begin{array}{l}38 \\
(21.2)\end{array}$ & $62(34.6)$ & $\begin{array}{l}56 \\
(31.3)\end{array}$ \\
\hline Anxiety/tension & $98(54.4)$ & $57(32.0)$ & $\begin{array}{l}46 \\
(25.8)\end{array}$ & $46(25.8)$ & $\begin{array}{l}29 \\
(16.3)\end{array}$ \\
\hline Tearful/sensitive to rejection & $97(53.9)$ & $83(46.6)$ & $\begin{array}{l}26 \\
(14.6)\end{array}$ & $32(18.0)$ & $\begin{array}{l}37 \\
(20.8)\end{array}$ \\
\hline Depressed mood/hopelessness & $104(57.8)$ & $78(43.8)$ & $\begin{array}{l}40 \\
(22.5)\end{array}$ & 35 (19.7) & $\begin{array}{l}25 \\
(14.0)\end{array}$ \\
\hline Decreased interest in work activities & $\begin{array}{l}83(46.1) \\
\text { (All three) }\end{array}$ & $65(36.3)$ & $\begin{array}{l}52 \\
(29.1)\end{array}$ & $41(22.9)$ & $\begin{array}{l}21 \\
(11.7)\end{array}$ \\
\hline Decreased interest in home activities & & $53(29.8)$ & $\begin{array}{l}55 \\
(30.9)\end{array}$ & $44(24.7)$ & $\begin{array}{l}26 \\
(14.6)\end{array}$ \\
\hline Decreased interest in social activities & & $79(44.1)$ & $\begin{array}{l}49 \\
(27.4)\end{array}$ & $30(16.7)$ & $\begin{array}{l}21 \\
(11.7)\end{array}$ \\
\hline Difficulty concentrating & $57(31.7)$ & $96(53.6)$ & $\begin{array}{l}53 \\
(29.6)\end{array}$ & $21(11.7)$ & $9(5.0)$ \\
\hline Fatigue/lack of energy & $134(74.4)$ & $47(26.9)$ & $\begin{array}{l}56 \\
(32.0)\end{array}$ & $48(27.4)$ & $\begin{array}{l}24 \\
(13.7)\end{array}$ \\
\hline Overeating/food cravings & $98(54.4)$ & $92(51.7)$ & $\begin{array}{l}27 \\
(15.2)\end{array}$ & $25(14.0)$ & $\begin{array}{l}34 \\
(19.1)\end{array}$ \\
\hline Insomnia & $95(52.8)$ & $\begin{array}{l}104 \\
(58.4)\end{array}$ & $\begin{array}{l}36 \\
(20.2)\end{array}$ & $21(11.8)$ & $17(9.6)$ \\
\hline Hypersomnia (needing more sleep) & & $76(42.7)$ & $\begin{array}{l}39 \\
(21.9)\end{array}$ & $33(18.5)$ & $\begin{array}{l}30 \\
(16.9)\end{array}$ \\
\hline $\begin{array}{l}\text { Feeling overwhelmed or out of } \\
\text { control }\end{array}$ & $66(36.7)$ & $\begin{array}{l}101 \\
(57.4)\end{array}$ & $\begin{array}{l}22 \\
(12.5)\end{array}$ & $37(21.0)$ & $16(9.1)$ \\
\hline Physical symptoms & $156(86.7)$ & $16(9.0)$ & $\begin{array}{l}56 \\
(31.5)\end{array}$ & $65(36.5)$ & $\begin{array}{l}41 \\
(23.0)\end{array}$ \\
\hline
\end{tabular}

PSST, Premenstrual Symptoms Screening Tool; MINI-U, The Mini International Neuropsychiatric Interview,

Module U. 


\begin{tabular}{|c|c|c|c|c|c|}
\hline & $\begin{array}{l}\text { MINI-U } \\
\text { (Yes) }\end{array}$ & Not at all & Mild & Moderate & Severe \\
\hline Work efficiency/productivity & $\begin{array}{l}94(52.2) \\
\text { (Altogether) }\end{array}$ & $85(47.8)$ & $\begin{array}{l}45 \\
(25.3)\end{array}$ & $35(19.7)$ & $13(7.3)$ \\
\hline Relationship with co-workers & & $\begin{array}{l}108 \\
(61.4)\end{array}$ & $\begin{array}{l}41 \\
(23.3)\end{array}$ & $19(10.8)$ & $8(4.5)$ \\
\hline Relationship with family & & $69(38.8)$ & $\begin{array}{l}57 \\
(32.0)\end{array}$ & $36(20.2)$ & $16(9.0)$ \\
\hline Your social life activities & & $89(50.0)$ & $\begin{array}{l}49 \\
(27.5)\end{array}$ & $29(16.3)$ & $11(6.2)$ \\
\hline Home responsibilities & & $89(50.0)$ & $\begin{array}{l}55 \\
(30.9)\end{array}$ & $23(12.9)$ & $11(6.2)$ \\
\hline \multicolumn{6}{|c|}{$\begin{array}{l}\text { PSST, Premenstrual Symptoms Screening Tool; MINI-U, The Mini International Neuropsychiatric } \\
\text { Interview, }\end{array}$} \\
\hline \multicolumn{6}{|l|}{ Module U. } \\
\hline
\end{tabular}

According to the symptoms assessed by the PSST, the most common severe symptoms were anger or irritability (31.3\%), physical symptoms $(23 \%)$ and being tearful or sensitive to rejection $(20.8 \%)$. The most common moderate symptoms reported by our participants were physical symptoms (36.5\%), anger or irritability (34.6\%) and fatigue or lack of energy (27.4\%). The severity of these symptoms affected mostly their relationships with their family (moderate, $20.2 \%$ and severe $9 \%$ ) and their work efficiency or productivity (moderate, $19.7 \%$ and severe $7.3 \%$ ). The symptoms that were least experienced by our participants were feeling overwhelmed or out of control (57.4\%), insomnia (58.4\%), and difficulty concentrating (53.6\%). According to the MINI-U, the most common symptoms were physical symptoms $(86.7 \%)$, fatigue or lack of energy $(74.4 \%)$ and anger or irritability $(73.3 \%)$. The least reported symptoms were difficulty concentrating (31.7\%) and feeling overwhelmed or out of control (36.7\%).

\section{Scores on PSST items by MINI-U dichotomous responses (Table 5)}


Table 5

Scores on PSST items by MINI-U dichotomous responses

\begin{tabular}{|c|c|c|c|c|c|}
\hline \multirow[b]{3}{*}{ PSST } & \multicolumn{5}{|c|}{ MINI Module U } \\
\hline & \multicolumn{2}{|l|}{ No } & \multicolumn{3}{|l|}{ Yes } \\
\hline & Median & IQR & Median & IQR & P-Value \\
\hline Anger/irritability & 2 & 2 & 3 & 1 & $<0.001$ \\
\hline Anxiety/tension & 2 & 1 & 3 & 2 & $<0.001$ \\
\hline Tearful/sensitive to rejection & 1 & 0 & 3 & 2 & $<0.001$ \\
\hline Depressed mood/hopelessness & 1 & 1 & 2 & 2 & $<0.001$ \\
\hline Decreased interest in work activities & 1 & 1 & 3 & 1 & $<0.001$ \\
\hline Decreased interest in home activities & 2 & 1 & 3 & 1 & $<0.001$ \\
\hline Decreased interest in social activities & 1 & 1 & 3 & 1 & $<0.001$ \\
\hline Difficulty concentrating & 1 & 1 & 2 & 1 & $<0.001$ \\
\hline Fatigue/lack of energy & 1 & 1 & 2 & 1 & $<0.001$ \\
\hline Overeating/food cravings & 1 & 1 & 2 & 2 & $<0.001$ \\
\hline Insomnia & 1 & 1 & 1.5 & 2 & 0.004 \\
\hline Hypersomnia (needing more sleep) & 1 & 1 & 3 & 3 & $<0.001$ \\
\hline Feeling overwhelmed or out of control & 1 & 1 & 3 & 2 & $<0.001$ \\
\hline Physical symptoms & 2 & 2 & 3 & 2 & $<0.001$ \\
\hline \multicolumn{6}{|l|}{ Symptoms interfered with: } \\
\hline Work efficiency/productivity & 1 & 1 & 2 & 2 & $<0.001$ \\
\hline Relationship with co-workers & 1 & 0 & 2 & 2 & $<0.001$ \\
\hline Relationship with family & 1 & 1 & 2 & 1 & $<0.001$ \\
\hline Your social life activities & 1 & 1 & 2 & 2 & $<0.001$ \\
\hline Home responsibilities & 1 & 1 & 2 & 2 & $<0.001$ \\
\hline
\end{tabular}

PSST, Premenstrual Symptoms Screening Tool; MINI-U, The Mini International Neuropsychiatric Interview, Module U.

We used the Wilcoxon-Mann-Whitney test to assess if the ordinal scores on the PSST items are different between those who answered Yes vs. No on the MINI-U. Among the MINI- $U$ dichotomous answers, all PSST ratings were significantly higher among participants who answered Yes $(p<.01)$. Participants who answered No on the MINI-U had a median rating of 1 (Not at all) for all the symptoms with the exception of 
(1) anger or irritability, (2) anxiety or tension, (3) decreased interest in home activities, and (4) physical symptoms where the median rating was 2 (mild). Participants who answered Yes had a median rating from 1.5 (not at all to mild) to 3 (moderate). Out of the 14 symptoms assessed, nine had a median rating of 3 (moderate), four symptoms had a median rating of 2 (mild), and one symptom had a median rating of 1.5 (not at all to mild) (Table 5). The median rating of the interference of these symptoms on work or productivity, relationship with family, relationship with co-workers, relationship with family, on social life activities and home responsibilities was 2 (mild).

\section{Cut-off scores on PSST items by MINI-U dichotomous responses (Table 6)}


Table 6

The cut-off scores of the PSST items with the corresponding MINI-U items

\begin{tabular}{|c|c|c|c|c|c|c|c|c|}
\hline Symptom & PSST & $\begin{array}{l}\text { MINI- } \\
\text { U }\end{array}$ & AUC & $\begin{array}{l}95 \% \\
\mathrm{Cl}\end{array}$ & $J$ & $\begin{array}{l}\text { Cut- } \\
\text { off }\end{array}$ & Sensitivity & Specificity \\
\hline Anger/irritability & 1 & $\begin{array}{l}\text { U3 - } \\
\text { D }\end{array}$ & $0.804^{\star *}$ & $\begin{array}{l}(0.73- \\
0.88)\end{array}$ & 0.48 & 2.5 & 0.780 & 0.696 \\
\hline Anxiety/tension & 2 & $\begin{array}{l}\text { U3 - } \\
\text { B }\end{array}$ & 0.740 ** & $\begin{array}{l}(0.67- \\
0.81)\end{array}$ & 0.41 & 2.5 & 0.608 & 0.800 \\
\hline $\begin{array}{l}\text { Tearful/sensitive to } \\
\text { rejection }\end{array}$ & 3 & $\begin{array}{l}\text { U3 - } \\
\text { C }\end{array}$ & $0.835^{\star \star}$ & $\begin{array}{l}(0.77- \\
0.90)\end{array}$ & 0.63 & 1.5 & 0.814 & 0.812 \\
\hline $\begin{array}{l}\text { Depressed } \\
\mathrm{mood} / \text { hopelessness }\end{array}$ & 4 & $\begin{array}{l}\text { U3 - } \\
\mathrm{A}\end{array}$ & $0.735^{\star \star}$ & $\begin{array}{l}(0.66- \\
0.81)\end{array}$ & 0.38 & 1.5 & 0.718 & 0.658 \\
\hline $\begin{array}{l}\text { Decreased interest in } \\
\text { work activities }\end{array}$ & 5 & $\begin{array}{l}\text { U3 - } \\
\text { E }\end{array}$ & $0.752^{\star *}$ & $\begin{array}{l}(0.68- \\
0.83)\end{array}$ & 0.45 & 2.5 & 0.590 & 0.860 \\
\hline $\begin{array}{l}\text { Decreased interest in } \\
\text { home activities }\end{array}$ & 6 & $\begin{array}{l}\mathrm{U} 3- \\
\mathrm{E}\end{array}$ & $0.743^{\star *}$ & $\begin{array}{l}(0.67- \\
0.82)\end{array}$ & 0.39 & 2.5 & 0.602 & 0.783 \\
\hline $\begin{array}{l}\text { Decreased interest in } \\
\text { social activities }\end{array}$ & 7 & $\begin{array}{l}\text { U3 - } \\
\text { E }\end{array}$ & $0.768^{\star *}$ & $\begin{array}{l}(0.70- \\
0.84)\end{array}$ & 0.43 & 1.5 & 0.795 & 0.634 \\
\hline $\begin{array}{l}\text { Difficulty } \\
\text { concentrating }\end{array}$ & 8 & $\begin{array}{l}\text { U3 - } \\
\mathrm{F}\end{array}$ & $0.806^{\star \star}$ & $\begin{array}{l}(0.74- \\
0.88)\end{array}$ & 0.55 & 1.5 & 0.842 & 0.706 \\
\hline $\begin{array}{l}\text { Fatigue/lack of } \\
\text { energy }\end{array}$ & 9 & $\begin{array}{l}\text { U3 - } \\
\text { G }\end{array}$ & 0.728 ** & $\begin{array}{l}(0.64- \\
0.81)\end{array}$ & 0.36 & 1.5 & 0.823 & 0.535 \\
\hline $\begin{array}{l}\text { Overeating/food } \\
\text { cravings }\end{array}$ & 10 & $\begin{array}{l}\text { U3 - } \\
\mathrm{H}\end{array}$ & $0.700 * \star$ & $\begin{array}{l}(0.62- \\
0.78)\end{array}$ & 0.36 & 2.5 & 0.495 & 0.861 \\
\hline Insomnia & 11 & U3 - I & $0.614^{\star}$ & $\begin{array}{l}(0.53- \\
0.70)\end{array}$ & 0.17 & 1.5 & 0.500 & 0.671 \\
\hline Hypersomnia & 12 & U3 - I & $0.732^{\star \star}$ & $\begin{array}{l}(0.66- \\
0.81)\end{array}$ & 0.39 & 2.5 & 0.537 & 0.852 \\
\hline $\begin{array}{l}\text { Feeling overwhelmed } \\
\text { or out of control }\end{array}$ & 13 & U3 - & $0.714^{\star \star}$ & $\begin{array}{l}(0.63- \\
0.80)\end{array}$ & 0.39 & 1.5 & 0.667 & 0.722 \\
\hline Physical symptoms & 14 & $\begin{array}{l}\text { U3 - } \\
\mathrm{K}\end{array}$ & $0.723^{\star *}$ & $\begin{array}{l}(0.60- \\
0.85)\end{array}$ & 0.33 & 2.5 & 0.643 & 0.682 \\
\hline \multicolumn{9}{|l|}{$\begin{array}{l}\text { Symptoms interfered } \\
\text { with: }\end{array}$} \\
\hline $\begin{array}{l}\text { Work } \\
\text { efficiency/productivity }\end{array}$ & $A$ & $\mathrm{U} 2$ & 0.696 ** & $\begin{array}{l}(0.62- \\
0.77)\end{array}$ & 0.32 & 1.5 & 0.677 & 0.639 \\
\hline $\begin{array}{l}\text { Relationship with co- } \\
\text { workers }\end{array}$ & B & $\mathrm{U} 2$ & 0.674 ** & $\begin{array}{l}(0.60- \\
0.75)\end{array}$ & 0.30 & 1.5 & 0.527 & 0.771 \\
\hline
\end{tabular}




\begin{tabular}{|lcccccccc|}
\hline Symptom & PSST & $\begin{array}{l}\text { MINI- } \\
\text { U }\end{array}$ & AUC & $\begin{array}{l}95 \% \\
\text { Cl }\end{array}$ & J & $\begin{array}{l}\text { Cut- } \\
\text { off }\end{array}$ & Sensitivity & Specificity \\
\hline $\begin{array}{l}\text { Relationship with } \\
\text { family }\end{array}$ & C & U2 & $0.686^{\star *}$ & $\begin{array}{l}(0.61- \\
0.76)\end{array}$ & 0.30 & 1.5 & 0.753 & 0.542 \\
\hline $\begin{array}{l}\text { Your social life } \\
\text { activities }\end{array}$ & D & U2 & $0.729^{* *}$ & $\begin{array}{l}(0.65- \\
0.80)\end{array}$ & 0.38 & 1.5 & 0.677 & 0.699 \\
\hline Home responsibilities & E & U2 & $0.724^{\star *}$ & $\begin{array}{l}(0.65- \\
0.80)\end{array}$ & 0.40 & 1.5 & 0.688 & 0.711 \\
\hline
\end{tabular}

ROC analyses showed that all areas under the curves (AUCs) were significant with the cut-off scores (and the corresponding sensitivity and specificity values using Youden index) on the corresponding PSST items using the MINI-U questions as the gold standard. The cut- off scores for the items on anger or irritability, anxiety or tension, decreased interest in work or home activities, overeating, hypersomnia, and physical symptoms were 2.5 on the corresponding PSST items. The remaining items had a corresponding cut-off score of 1.5. The balanced sensitivity and specificity values for all the corresponding cut-off scores were good ranging from 0.50 to 0.86 .

\section{Discussion}

The first aim of this study was to compare the responses between the dichotomous MINI-U responses and the scores on the PSST items. Our study showed a discrepancy in the prevalence of the diagnosis of PMDD between the MINI criteria (46.7\%) and PSST criteria (13.9\%). The discrepancy between the two could be attributed to the dichotomous nature of the questions in MINI-U that assess only the presence or absence of symptoms, while those in PSST focuses more on the severity of symptoms to establish the diagnosis of PMDD. The high prevalence of PMDD is also higher than that reported worldwide (5-8\%) [10]. Other countries such as Iran [22], Jordan [1], India [23] and Brazil [24] reported a similarly high prevalence of PMDD suggesting that there are ethnic variations in the prevalence of PMDD. It also highlights the need for an efficient and valid diagnosis of PMDD to recognize these patients and initiate treatment as early as needed. In a comparison among the participants who answered positively vs. negatively on the MINI questions, we found that all PSST symptom ratings were significantly higher among those who answered positively. Most symptoms on PSST had a median rating of "moderate" indicating clinical significance (Table 5). PSST severity measures might allow distinguishing which symptoms are clinically significant. Previous studies reported that $20 \%$ of women have subthreshold PMDD and can benefit from further monitoring and treatment [25]. The most commonly reported moderate/severe symptoms for our population were anger/irritability ( $34.6 \%$ moderate, $31.3 \%$ severe), anxiety ( $25.8 \%$ moderate, $16.3 \%$ severe), and physical symptoms (36.5\% moderate, $23.0 \%$ severe) (Table 4$)$. These were also found to be common complaints among Jordanian and Emirati women [26,27]. One of the major concerns with the MINI and PSST is the requirement to have daily ratings of symptoms for a minimum of two cycles as per DSM criteria to confirm the cyclical presence of symptoms for moderate/severe PMS and PMDD. Keeping a daily diary before initiating treatment may cause resistance for women to seek treatment. In research settings, an 
epidemiological study found that $30 \%$ of women refused to participate in a study because they did not want to fill daily ratings and the latter is usually associated with a high dropout rate [28]. Our results suggest that the severity measures of PSST can capture the PMDD cases who would benefit from treatment initiation.

The second aim of the study was to establish the cut-off scores on the dimensional PSST items by using the categorical MINI-U as a gold standard. All the cut-off scores showed significant differentiation and ranged from 1.5 to 2.5 with adequate sensitivity and specificity (Table 6). The MINI-U is a diagnostic instrument whereas the PSST is both a diagnostic and dimensional instrument [17]. However, both scales are based on DSM-IV-TR criteria for the diagnosis of PMDD and are therefore assessing the same symptoms (Table 1). Cross-validating these instruments showed that most symptoms corresponding to a Yes in the MINI-U had a cut-off score of 1.5 or a rating of at least Mild on the corresponding PSST items. Affirmative answers to anger/irritability, anxiety/tension, decreased interest in home activities and physical symptoms in the MINI-U had a corresponding cut-off score of 2.5 or at least moderate symptoms in the PSST, meaning that the latter captured mainly the moderate to severe cases. However, the challenge is to distinguish which women need treatment from those whose symptoms are not clinically relevant [28]. Moderate/severe PMS and PMDD are poorly diagnosed and mostly untreated conditions [29]. Furthermore, women with moderate/severe PMS symptoms have a higher rate of work absences and increased medical expenses [2]. These women can, therefore, benefit from a prompt referral and timely treatment [2].

\section{Conclusion}

In conclusion, our results showed a significant relationship between the responses on the Arabic MINI-U and PSST. Participants who answered positively on the MINI had significantly higher ratings and relevant cut-off scores on the corresponding PSST items. This cross-validation gives reassurance that the MINI-U provides an adequate assessment for the probable diagnosis of PMDD and that the severity measures of the PSST can recognize patients with moderate/severe PMS and PMDD who would definitely benefit from immediate treatment. Thus, there is a clear advantage of using PSST to early identify these patients with moderate/severe symptoms who should not wait for the daily measures of MINI-U.

\section{Abbreviations}

AUC

area under the curve

CBT

Cognitive behavioural therapy

DSM

Diagnostic and Statistical Manual of Mental Disorders ICD:International Classification of Diseases IQR

Interquartile range

MINI

Mini International Neuropsychiatric Interview PMS:Premenstrual syndrome PMDD 
Premenstrual dysphoric disorder PSST:Premenstrual Symptoms Screening Tool ROC:Receiving operating characteristic

SD

Standard deviation

\section{Declarations}

\section{Ethical approval}

The study protocol was approved by the institutional review boards of Hamad Medical Corporation and Weill Cornell Medicine in Doha, Qatar. Participation in the study was voluntary and all subjects provided written informed consent before joining the study.

\section{Consent for publication}

Not applicable.

\section{Availability of data and materials}

The datasets analysed during the current study are not available publicly available due to privacy or ethical restrictions but are available from the corresponding author on reasonable request.

\section{Competing interests}

The authors have no competing interests.

\section{Funding}

This study was part of a project funded solely by the Qatar National Research Fund (QNRF) granted to [name deleted] UREP 10-022-3-005. QNRF did not have any additional role in the study design, data collection or analysis, interpretation of data, decision to publish, or preparation of the manuscript.

\section{Authors' contribution}

$\mathrm{RC}$ contributed to statistical analysis, data interpretation and manuscript writing. RE contributed to study design and recruitment of subjects. ZM contributed to statistical analysis, data interpretation and finalizing the results. HA is the principal investigator on this project, contributed to protocol and study design, data interpretation, manuscript writing and revisions, and supervised all study procedures. All authors read and approved this manuscript. 


\section{Acknowledgements}

Not applicable.

\section{References}

1. Hamaideh SH, Al-Ashram SA, Al-Modallal H: Premenstrual syndrome and premenstrual dysphoric disorder among Jordanian women. J Psychiatr Ment Health Nurs 2014, 21(1):60-68.

2. Hofmeister S, Bodden S: Premenstrual Syndrome and Premenstrual Dysphoric Disorder. Am Fam Physician 2016, 94(3):236-240.

3. Hantsoo L, Epperson CN: Premenstrual Dysphoric Disorder: Epidemiology and Treatment. Current psychiatry reports 2015, 17(11):87.

4. Ryu A, Kim TH: Premenstrual syndrome: A mini review. Maturitas 2015, 82(4):436-440.

5. Schmidt PJ, Nieman LK, Danaceau MA, Adams LF, Rubinow DR: Differential behavioral effects of gonadal steroids in women with and in those without premenstrual syndrome. N Engl J Med 1998, 338(4):209-216.

6. Grady-Weliky TA: Clinical practice. Premenstrual dysphoric disorder. N Engl J Med 2003, 348(5):433438.

7. Yonkers KA, Brown C, Pearlstein TB, Foegh M, Sampson-Landers C, Rapkin A: Efficacy of a new lowdose oral contraceptive with drospirenone in premenstrual dysphoric disorder. Obstet Gynecol 2005, 106(3):492-501.

8. Shah NR, Jones JB, Aperi J, Shemtov R, Karne A, Borenstein J: Selective serotonin reuptake inhibitors for premenstrual syndrome and premenstrual dysphoric disorder: a meta-analysis. Obstet Gynecol 2008, 111(5):1175-1182.

9. Steiner M, Pearlstein T, Cohen LS, Endicott J, Kornstein SG, Roberts C, Roberts DL, Yonkers K: Expert guidelines for the treatment of severe PMS, PMDD, and comorbidities: the role of SSRIs. $J$ Womens Health (Larchmt) 2006, 15(1):57-69.

10. Angst J, Sellaro R, Merikangas KR, Endicott J: The epidemiology of perimenstrual psychological symptoms. Acta Psychiatr Scand 2001, 104(2):110-116.

11. Freeman EW: Premenstrual syndrome and premenstrual dysphoric disorder: definitions and diagnosis. Psychoneuroendocrinology 2003, 28 Suppl 3:25-37.

12. American Psychiatric Association: Diagnostic and Statistical Manual of Mental Disorders, 5 th edn. Arlington, VA;

13. American Psychiatric Association: Diagnostic and Statistical Manual of Mental Disorders, 4th edn. Washington, DC;

14. Lecrubier Y, Sheehan DV, Weiller E, Amorim P, Bonora I, Sheehan KH, Janavs J, Dunbar GC: The Mini International Neuropsychiatric Interview (MINI). A short diagnostic structured interview: Reliability and validity according to the CIDI. Eur Psychiat 1997, 12(5):224-231. 
15. Sheehan DV, Lecrubier Y, Sheehan KH, Amorim P, Janavs J, Weiller E, Hergueta T, Baker R, Dunbar GC: The Mini-International Neuropsychiatric Interview (M.I.N.I.): the development and validation of a structured diagnostic psychiatric interview for DSM-IV and ICD-10. J Clin Psychiatry 1998, 59 Suppl 20:22-33;quiz 34-57.

16. Amorim P, Lecrubier Y, Weiller E, Hergueta T, Sheehan D: DSM-IH-R Psychotic Disorders: procedural validity of the Mini International Neuropsychiatric Interview (MINI). Concordance and causes for discordance with the CIDI. Eur Psychiatry 1998, 13(1):26-34.

17. Steiner M, Macdougall M, Brown E: The premenstrual symptoms screening tool (PSST) for clinicians. Arch Womens Ment Health 2003, 6(3):203-209.

18. Smith MJ, Schmidt PJ, Rubinow DR: Operationalizing DSM-IV criteria for PMDD: selecting symptomatic and asymptomatic cycles for research. J Psychiatr Res 2003, 37(1):75-83.

19. Johnson SR: Premenstrual syndrome, premenstrual dysphoric disorder, and beyond: a clinical primer for practitioners. Obstet Gynecol 2004, 104(4):845-859.

20. Takeda T, Tasaka K, Sakata M, Murata Y: Prevalence of premenstrual syndrome and premenstrual dysphoric disorder in Japanese women. Arch Womens Ment Health 2006, 9(4):209-212.

21. IBM Corp. Released 2017: IBM SPSS Statistics for Macintosh, Version 0. Armonk, NY: IBM Corp.

22. Hariri FZ, Moghaddam-Banaem L, Siah Bazi S, Saki Malehi A, Montazeri A: The Iranian version of the Premenstrual Symptoms Screening Tool (PSST): a validation study. Arch Womens Ment Health 2013, 16(6):531-537.

23. Mishra A, Banwari G, Yadav P: Premenstrual dysphoric disorder in medical students residing in hostel and its association with lifestyle factors. Ind Psychiatry J 2015, 24(2):150-157.

24. Camara RA, Kohler CA, Frey BN, Hyphantis TN, Carvalho AF: Validation of the Brazilian Portuguese version of the Premenstrual Symptoms Screening Tool (PSST) and association of PSST scores with health-related quality of life. Braz J Psychiatry 2017, 39(2):140-146.

25. Hall E, Steiner M: Psychiatric symptoms and disorders associated with reproductive cyclicity in women: advances in screening tools. Womens Health (Lond) 2015, 11(3):397-415.

26. Albsoul-Younes A, Alefishat E, Farha RA, Tashman L, Hijjih E, AlKhatib R: Premenstrual syndrome and premenstrual dysphoric disorders among Jordanian women. Perspect Psychiatr Care 2018, 54(3):348353.

27. Osman OT, Sabri S, Zoubeidi T, Alharbi Al, Rizk D, Narchi H, Souid AK: Prevalence, Severity, and Correlates of Premenstrual Dysphoric Disorder Symptoms Among Women in the Arabian Peninsula. Prim Care Companion CNS Disord 2017, 19(4).

28. Henz A, Ferreira CF, Oderich CL, Gallon CW, Castro JRS, Conzatti M, Fleck MPA, Wender MCO: Premenstrual Syndrome Diagnosis: A Comparative Study between the Daily Record of Severity of Problems (DRSP) and the Premenstrual Symptoms Screening Tool (PSST). Rev Bras Ginecol Obstet 2018, 40(1):20-25.

29. Panay N, Fenton A: Severe PMS/PMDD - is it time for a new approach? Climacteric 2015, 18(3):331332. 